\title{
C) GitistóróRICA
}

\section{Masculinos \& Masculinidades: performances, invenções e práticas}

\author{
Rafael França Gonçalves dos Santos* \\ Natanael de Freitas Silva**
}

Inicialmente, gostaríamos de registrar que este dossiê é publicado em um momento crítico da nossa história recente: a pandemia da covid-19, que alterou hábitos e práticas cotidianas, deslocou nossa maneira de ser e estar no mundo, inclusive no âmbito acadêmico, acelerando e forçando uma urgente adaptação a outros modos de vida - mais recluso e individualizado - e rotinas de escrita, de interação social e de trabalho mediadas pelas tecnologias digitais. Ao longo desse processo, no qual ainda estamos imersos, destacamos também que a chamada para este dossiê foi aprovada antes desse cenário de crise sanitária, mas em um momento em que já experimentávamos uma profunda crise política e social, acentuada pela desigualdade de gênero e as violências contra as populações mais vulneráveis.

Nossa proposta inicial foi acolher reflexões e análises diversas acerca das narrativas, das práticas, dos ritos e das produções discursivas contemporâneas sobre os modos de produção e subjetivação masculina, bem como os itinerários sobre ou em torno das experiências das masculinidades. Assim, reconhecemos a relevância e destaque que assume a intersecção dos estudos feministas, das relações de gênero e das sexualidades, como condição de possibilidades para a emergência dessas análises que ora serão apresentadas no dossiê.

Logo, não poderíamos deixar de agradecer a cada autor e autora que se empenhou em escrever e submeter seus manuscritos sob condições atípicas de existência, assim como o trabalho dos pareceristas e dos editores da Revista Crítica Histórica, persistindo e resistindo em tempos de insidiosos ataques ao conhecimento e à universidade pública brasileira.

No Brasil, desde os anos 1990 (MATOS, 2002; SOUZA, 2009; SILVA, 2015, 2018; OLIVEIRA, 20I5), os estudos sobre as masculinidades têm se constituído num amplo e

\footnotetext{
" Doutor em História pela Universidade Federal Rural do Rio de Janeiro (UFRRJ). Membro do LabQueer - Laboratório de estudos das relações de gênero, masculinidades e transgêneros/UFRRJ. Email: rafael.fgs@hotmail.com

** Doutorando pelo Programa de Pós-Graduação em História (PPHR/UFRRJ/CAPES). Membro do LabQueer - Laboratório de estudos das relações de gênero, masculinidades e transgêneros/UFRRJ e do Laboratório de Educação em Direitos Humanos, da UFABC. E-mail: natanaelfreitass@gmail.com
} 
complexo campo de análise e investigação sobre os modos de construção dos homens, dos masculinos e das masculinidades. Desta forma, antropólogos/as, sociólogos/as e historiadores/as têm matizado o debate em torno de temas como: violências (CECCHETTO, 2004), sexualidades (SEFFNER, 2003), saúde masculina (GOMES, 2008), corporalidades e indumentária (SIMILI; BONADIO, 20I7), "crise" das masculinidades (SIQUEIRA, 2006), transmasculinidades (ÁVILA, 20I4), relações de amizade (NASCIMENTO, 20II; SANTOS, 20I6), masculinidades e relações raciais (MISKOLCI, 2012; VIGOYA, 2007, 2018; RESTIER; SOUZA, 2019), entre tantos outros. A maioria desses estudos é produzida a partir de uma perspectiva relacional do gênero (MATOS, 2002; GROSSI, 2004; GIFFIN, 2005; PEDRO, 20II), mostrando que, se as mulheres não foram sempre as mesmas ao longo da história, os homens (AMBRA, 2015), muito menos.

De acordo com o historiador Durval Muniz Albuquerque Júnior, fazer uma história dos homens é pensá-los "não mais como indivíduos ou partícipes de feitos coletivos, mas como gênero, não a história de homens como agentes do processo histórico, mas como produtos deste mesmo processo" isto é, "a história de homens construindo-se como tal, a história da produção de subjetividades masculinas, em suas várias formas, a história da multiplicidade de ser homem" (2013, p. 23).

A partir dessa premissa, atenderam ao nosso convite mais de 20 pesquisadores e pesquisadoras que, individual ou coletivamente, colaboraram na reflexão, análise e compreensão das múltiplas maneiras de ser e de se fazer homem no Brasil e fora dele (KIMMEL, 1998, 2005, 2016; WELZER-LANG, 200I, 2004; CONNELL, MESSERSCHMIDT, 2013). Nos campos historiográfico, sociológico e antropológico, mas também na educação, na psicologia, entre outros, são muitas as contribuições que permitem mapearmos a produção das subjetividades masculinas e assim aguçar a reflexão que, ao tensionar esses campos disciplinares, evidenciam o potencial do gênero enquanto categoria de análise histórica (SCOTT, 1994).

Todavia, antes de situarmos cada texto, gostaríamos de destacar também a imagem que integra a capa deste Dossiê na Revista Crítica Histórica. Sob o olhar e foco atento das lentes do fotógrafo brasileiro Leonardo Barros Medeiros, temos a fotografia Guardarropa, protagonizada por um modelo espanhol e que faz parte da série ACasa|OCorpo. A partir de uma articulação entre as imagens, as palavras e as coisas, conforme sugere Didi-Huberman (2012), entendemos que a imagem produz um corte na realidade, mobiliza sentidos, expressa momentos e nos permite observá-la como um 
sintoma de possíveis mudanças e transformações no espectro das masculinidades. Além disso, a articulação/interposição entre imagem e a palavra, nos possibilita vislumbrar a dimensão poética imanente das narrativas históricas (HUSSAK, 2020). Sendo assim, apresentamos, a seguir, uma breve síntese dos treze textos selecionados para compor este Dossiê, Masculinos \& Masculinidades: performances, invenções e práticas.

No artigo que abre o dossiê, Fernando Botton promove um encontro teórico refinado entre Raewyn Connell e Judith Butler. Em Considerações críticas acerca das teorias de Raewyn Connell e Judith Butler para o estudo das masculinidades, Botton apresenta um balanço crítico entre a sociologia connelliana das masculinidades e a teoria butleriana das relações de gênero, focalizando as tensões entre distintas teorizações e concepções de gênero a partir de uma relação assimétrica entre as epistemologias do Sul e do Norte Global. Mediador crítico desse encontro entre a socióloga australiana e a filósofa estadunidense, Botton destaca e evidencia apropriações, aproximações políticas entre a perspectiva queer, tal qual forjada por Judith Butler, e as masculinidades hegemônicas, signatárias dos escritos de Connell.

Kathleen Kate Dominguez Aguirre elabora uma profícua articulação das proposições de autores como María Lugones, Ochy Curiel e Raewyn Connell, em Masculinidades colonizadas e feminicídio na América Latina. Considerando essa abordagem interseccional das categorias gênero, masculinidades e raça, a autora engendra uma teorização sobre a permanência de um "continnum de violência patriarcal moderno-colonial", denunciando a persistente e histórica violência contra as mulheres (cis e trans) na América Latina.

A partir das críticas feministas, em Intervenções com homens para a equidade de gênero: crítica às abordagens individualizantes, Vanessa do Nascimento Fonseca analisa o predomínio de práticas individualizantes nas políticas de intervenção entre homens, no Brasil, desde os anos 1970, em torno da equidade de gênero. Argumenta-se que os homens são importantes aliados no enfrentamento dos efeitos danosos das relações de gênero, todavia, a autora defende ser necessário que os homens se engajem no enfrentamento e na luta interseccional contra um sistema que articula múltiplos pontos de opressão, indo além de mudanças focalizadas apenas no aspecto da conduta dos indivíduos mas recorrendo ao âmbito coletivo.

Tendo como fonte de análise um artefato audiovisual, em "Não é uma fantasia, este sou eu": Discussões sobre a representação e performance da masculinidade negra na série Sex Education (2019), Andrey da Cruz e João Paulo Baliscei apresentam 
Eric Effiong, um jovem negro gay que é o melhor amigo do protagonista da série britânica Sex Education (2019). A partir da desconstrução da personagem, os autores conseguem mapear a intersecção entre gênero e raça na constituição de uma masculinidade afeminada juvenil. Com destaque em três cenas da série, eles pontuam a desestabilização causada por Eric Effiong no sistema hegemônica da masculinidade, bem como a cobrança que o sistema faz sobre ele, com a concreta homofobia. A masculinidade negra e afeminada performada na série não é uma fantasia, há muitos Erics na sociedade britânica e também na brasileira.

Neste provocativo e instigante ensaio, $\mathrm{O}$ negro-lugar do homem preto brasileiro - episódios de racismo cotidiano em AmarElo (2019), Milton Ribeiro posiciona-se do lugar de homem negro paraense e dedica sua análise à obra de Emicida, AmarElo. O corpo é lido e percebido a partir do "negro-lugar" que ocupa na sociedade brasileira, enfrentando o racismo multifacetado. Em uma análise cuidadosa e problematizadora das letras das músicas que compõem o álbum, Ribeiro destaca as resistências e o ritmo da música também embala a leitura do texto. Ao final, ou mesmo antes disso, será impossível não buscar o álbum para ouvir cada música e atentar às palavras problematizadas no texto.

Salientando as dinâmicas específicas das relações de gênero no espaço escolar, no artigo Espaços de meninos: reflexões sobre a construção das masculinidades por adolescente de uma escola pública do município do Rio de Janeiro, Aline Carvalho apresenta uma importante iniciativa desenvolvida em uma escola pública no Rio de Janeiro, em que os meninos foram convidados a refletir e falar sobre si mesmos. Amparada na literatura sobre as masculinidades hegemônicas, Carvalho oferece aos leitores e leitoras uma instigante reflexão sobre como a educação escolar formal pode contribuir para a promoção da igualdade de gênero a partir da intervenção dialógica com meninos na fase da adolescência.

Ainda no campo educacional, mas agora focalizando outra personagem de destaque, em Professores homens nos anos iniciais: relações de gênero e formação docente, Thomaz Fonseca e Anderson Ferrari problematizam a, por vezes incômoda, presença de professores homens nos anos iniciais do Ensino Fundamental na rede pública municipal de Juiz de Fora, MG. A pesquisa demonstra o que comumente é percebido sem muita dificuldade: a rara presença de homens cisgêneros na docência dos anos iniciais; mas vai além disso, ao acompanhar os percursos trilhados por esses docentes, destacando suas estratégias e desafios enfrentados, particularmente ao 
terem que responder às interpelações de gênero que lhes foram colocadas ao longo de suas carreiras.

Tomando como ponto de partidas as mudanças históricas nas relações de trabalho e familiares, após os anos 1990, que possibilitaram o aumento de mulheres na condição de provedora do lar, em $\mathrm{O}$ declínio do homem provedor chefe de família: entre privilégios e ressentimentos, Caíque Diogo de Oliveira argumenta como as mudanças gestadas no capitalismo em sua dimensão neoliberal, tem feito com que muitos homens assumam uma posição ressentida diante das novas dinâmicas das relações de gênero e, por isso, acabam buscando num passado idílico um lugar de segurança e de mando masculino.

O que querem os homens pais? Qual o sentido da paternidade? Pode um filho ou filha fazer um homem gozar da paternidade? Há uma paternidade gestante? Essas são algumas das perguntas suscitadas pelo cuidadoso artigo de Camila Rebouças Fernandes Masculinidades e paternidades: novos olhares. Com um trabalho de campo realizado em um serviço de pré-natal na cidade do Rio de Janeiro, Fernandes aborda as expectativas de mudanças experienciadas por Io homens-pais que acompanhavam as mulheres-gestantes e oferece algumas pistas valiosas para pensarmos sobre as paternidades na contemporaneidade.

Em "Contra as investidas leoninas de uma indomável fera humana": masculinidades e família, Lucas Kosinski problematiza como determinada concepção de masculinidade hegemônica foi produzida e volatizada pelo discurso jurídico de Iraty, região interiorana do sudeste do Paraná, entre os anos de 1912 e I920. Na ocasião, o autor argumenta como um ideal de branquitude da população brasileira também foi agenciado nos discursos e práticas jurídicas e políticas no intuito de normatizar as relações de gênero através de uma judicialização das condutas, dos corpos e dos desejos.

Atenta ao carnaval em Porto Alegre/RS no final do século I9, em Masculinidades e carnaval na Porto Alegre do último quartel do século XIX, Caroline Leal dedica sua análise à emergência de duas importantes sociedades carnavalescas: Esmeralda e Os venezianos. Para realizar esse estudo histórico, Leal recorre à imprensa do período e percebe como masculinos e masculinidades foram gestados na reconfiguração da festa de rua e nos bailes fechados. Nesse exercício analítico, a autora também percebe a constituição de hierarquias produzidas a partir 
da classe social e destaca como esse "novo carnaval" fez parte de um jogo político mais amplo, que pretendia refletir e representar a modernização do país.

Daniel Welzer-Lang (200I) escreve sobre alguns espaços esportivos que são historicamente constituídos como masculinos, como os estádios de futebol. Sendo assim, no artigo Reflexões sobre os abalos da masculinidade hegemônica no futebol: das torcidas gays na década de 1970 aos campeonatos homossexuais da atualidade, Leonardo Martinelli reconhece essa realidade, mas é desafiado por torcedores de futebol da década de 1970 que criam as primeiras "torcidas gays". Martinelli percorre as publicações que noticiaram essa emergência no Sul e Sudeste do Brasil, problematiza os preconceitos sofridos por esses torcedores autodeclarados como homossexuais e chega até os dias atuais com a criação de campeonatos nacionais que congregam jogadores homossexuais. Da arquibancada ao campo de futebol, Martinelli encontra sujeitos que nessas últimas décadas provocaram a masculinidade hegemônica no futebol. Atento às estratégias mobilizadas por esses sujeitos, o autor também evidencia que a homofobia é como um zagueiro de marcação cerrada, mas que não impede os bons dribles e a invenção criativa de modos de ser homem no futebol.

A alimentação tem gênero? Ou melhor, os nossos hábitos de alimentação também podem ser generificados? A pergunta que mobiliza dois campos aparentemente distantes está presente na análise atenta produzida por Marina Pedersen no artigo Heteronormatividade e homofobia na propaganda de uma hamburgueria. No texto, a autora parte de uma propaganda de hambúrguer publicada no Facebook e desconstrói os símbolos e sentidos das masculinidades que são agenciados na tentativa de incentivar o consumo do hambúrguer; para tanto, demonstra como a carne é colocada como um alimento que além de masculino, serve para confirmar a heterossexualidade compulsória a ser assumida pelo "homem de verdade". Assim, o prato perfeito da heteronormatividade é composto pelo o consumo de carne, a homofobia e a heterossexualidade masculina.

Por fim, e a partir dos textos citados, enfatizamos a potência que o olhar amplo e multifacetado sobre as masculinidades pode nos proporcionar, complexificando e interrogando as narrativas hegemônicas, e denunciando criticamente as hierarquias sociais pautadas na naturalização da condição do homem, dos masculinos e das masculinidades, apontando outros e novos (des)caminhos na produção histórica, social, política e subjetiva das masculinidades, inclusive nesse tempo pandêmico. 


\section{C) GitistóróRICA}

\section{Referências}

ALBUQUERQUE JÚNIOR, Durval Muniz. Nordestino: uma invenção do falo. Uma

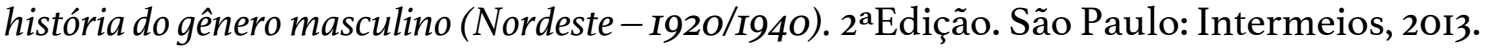
AMBRA, Pedro. O que é um homem? Psicanálise e história da masculinidade no Ocidente. São Paulo, Annablume, 2015.

ÁVILA, Simone N. Transmasculinidades: A emergência de novas identidades politicas e sociais. RJ: Editora Multifoco, 2014.

CECCHETTO, Fátima Regina. Violência e estilos de masculinidade. Rio de Janeiro: Editora FGV, 2004.

CONNELL, Robert. W; MESSERSCHMIDT, James W. Masculinidade hegemônica: repensando o conceito. Estudos Feministas, Florianópolis, 2I(I): 24I-282, janeiroabril/2OI3.

CORRÊA, Mariza; PISCITELLI, Adriana. "Flores do colonialismo": masculinidades numa perspectiva antropológica. Cadernos Pagu, Campinas, SP, n. II, p. 20I-229, jan. 2013.

DIDI-HUBERMAN, Georges. Quando as imagens tocam o real. Pós: Belo Horizonte, Belo Horizonte, v. 2, n. 4, p. 204-219, nov. 2012.

GIFFIN, Karen. A Inserção dos homens nos estudos de gênero: Contribuições de um sujeito histórica. Ciência \& Saúde Coletiva, Rio de Janeiro, v. Io, n.I, p. 47-58, 2005.

GOMES, Romeu. Sexualidade masculina, gênero e saúde. RJ: Editora FIOCRUZ, 2008.

GROSSI, Miriam Pillar. Masculinidades: uma revisão teórica. Antropologia em Primeira Mão. Florianópolis, 2004. p. 4-37.

Hussak, Pedro. A poética da história: Letícia Pumar e a produção artística como pesquisa. Rapsódia, (I4), 7I-85, 2020.

KIMMEL, Michael S. A produção simultânea de masculinidades hegemônicas e subalternas. Horiz. antropol., Porto Alegre, v. 4, n. 9, p. I03-II7, Oct. 1998.

. The history of man: essays in the history of American and British masculinities.

State University of New York Press, Albany. 2005.

Masculinidade como homofobia: medo, vergonha e silêncio na construção da identidade de gênero. Revista do Programa de Pós-graduação em Antropologia Social, Natal, v. 3, n. 4, p. 97-I24, 2016.

LOPES, Fábio Henrique. Masculinidade(s): reflexões em torno de seus aspectos históricos, sociais e culturais. Contemporâneos, Revista de Artes e Humanidades, n.8, Maio./out, p.I-I3, $201 \mathrm{I}$.

MATOS, Maria Izilda S. Desafios da pós-modernidade: sensibilidades e masculinidades. GÊNERO, Nitéroi, v.2, n.2, p.I75-I9I, I. sem. 2002.

MISKOLCI, Richard. O desejo da nação: masculinidade e branquitude no Brasil de fins do XIX. São Paulo: Annablume, 2012.

NASCIMENTO, Marcos Antonio Ferreira do. Improváveis Relações: produção de sentidos sobre o masculino no contexto de amizade entre homens homo e heterossexuais. Tese (Doutorado em Saúde Coletiva) - Instituto de Medicina Social, Universidade Estadual do Rio de Janeiro, Rio de Janeiro, 20II.

OLIVEIRA, Fábio Araújo. Historicização e institucionalização das masculinidades no Brasil. Tese (doutorado), Campinas, SP, 2015.

PEDRO, Joana. Relações de gênero como categoria transversal na historiografia contemporânea. Topoi, v. I2, n. 22, jan-jun, p. 270-283, 201 I. 
RESTIER, Henrique; SOUZA, Rolf Malungo de. Diálogos contemporâneos sobre homens negros e masculinidades. São Paulo: Ciclo Contínuo Editorial, 2019.

SANTOS, Rafael França Gonçalves. Bofes, mariconas e vícios: clientes e masculinidades na prostituição em Campos dos Goytacazes-RJ (20IO-2OII). Contemporâneos: Revista de Artes e Humanidades (Online), v. I4, p. I-23, 2016.

SCHPUN, Mônica Raisa (org.). Masculinidades. São Paulo: Boitempo Editorial; Santa Cruz do Sul, Edunisc, 2004.

SCOTT, Joan W. Prefácio a Gender and politics of history. In: Cadernos Pagu, n. 3. Campinas, Núcleo de Estudos de Gênero/ UNICAMP, 1994.

SEFFNER, Fenando. Derivas da masculinidade: representação, identidade e diferença no âmbito da masculinidade bissexual. Tese (doutorado), UFRGS, Porto Alegre, 2003.

SILVA, Natanael de Freitas. Historicizando as masculinidades: considerações e apontamentos à luz de Richard Miskolci e Albuquerque Júnior. História, Histórias, Brasília, v. 3, p. 7-22, 2015.

. Dzi Croquettes e as masculinidades disparatadas. HISTÓRIA, HISTÓRIAS, v. 6, p. 80-99, 2018.

SIMILI, Ivana Guilherme; BONADIO, Maria Claudia. Histórias do vestir masculino: narrativas de moda, beleza, elegância. Maringá: EDUEM, 2017.

SIQUEIRA, Elton Bruno Soares de. A crise da masculinidade nas dramaturgias de Nelson Rodrigues, Plínio Marcos e Newton Moreno. Tese (Doutorado em Teoria da Literatura) Centro de Artes e Comunicação, Universidade Federal de Pernambuco, Recife, 2006. SOUZA, Márcio Ferreira de. As análises de gênero e a formação do campo de estudos sobre a(s) masculinidade(s). Mediações, Londrina, v. I4, n.2, p. I23-I44, Jul/Dez. 2009.

SOUZA, Rolf Ribeiro de. As representações do homem negro e suas conseqüências. Revista Fórum Identidades, Ano 3, Volume 6, p. 97-II5, jul-dez de 2009.

WELZER-LANG, Daniel. A construção do masculino: dominação das mulheres e homofobia. Revista de Estudos Feministas, Florianópolis, v. 9, n. 2, p.46o-82, 200 I.

. Os homens e o masculino numa perspectiva de relações sociais de sexo. In:

SCHPUN, Mônica Raisa (org.). Masculinidades. São Paulo: Boitempo Editorial; Santa Cruz do Sul, Edunisc, 2004. p. I07-I28.

VIGOYA, Mara Viveros. As cores da masculinidade. Experiências interseccionais e práticas de poder na Nossa América. Editora: Papéis Selvagens, RJ, 2018.

- Teorías feministas y estudios sobre varones y masculinidades. Dilemas y desafíos recientes. La manzana de la discordia, Año 2, No. 4: 25- 36, Diciembre, 2007. 